\title{
Association between Daily Activities and Behavioral and Psychological Symptoms of Dementia in Community-Dwelling Older Adults with Memory Complaints by Their Families
}

\author{
Yuriko Ikeda ${ }^{1, *}$, Gwanghee Han ${ }^{2}$, Michio Maruta ${ }^{3,4}{ }^{\mathbb{C}}$, Maki Hotta ${ }^{5}$, Eri Ueno ${ }^{6}$ and \\ Takayuki Tabira ${ }^{1, *(1)}$ \\ 1 Graduate School of Health Science, Kagoshima University, Kagoshima 890-8544, Japan \\ 2 Department of Neuropsychiatry, Kumamoto University Hospital, Kumamoto 860-8556, Japan; \\ hans11057@gmail.com \\ 3 Doctoral Program of Clinical Neuropsychiatry, Graduate School of Health Science, Kagoshima University, \\ Kagoshima 890-8544, Japan; m.maru0111@gmail.com \\ 4 Department of Rehabilitation, Medical Corporation, Sanshukai, Okatsu Hospital, Kagoshima 890-0067, Japan \\ 5 Department of Behavioral Neurology and Neuropsychiatry, Osaka University United Graduate School of \\ Child Development, Osaka 565-0871, Japan; komaki@psy.med.osaka-u.ac.jp \\ 6 Department of Rehabilitation, Medical Corporation, Nissyoukai, Minamikagoshimasakura Hospital, \\ Kagoshima 890-0069, Japan; eueno@nissyoukai.or.jp \\ * Correspondence: yuriko@health.nop.kagoshima-u.ac.jp (Y.I.); tabitaka@health.nop.kagoshima-u.ac.jp (T.T.); \\ Tel.: +81-99-275-6783 (Y.I.); +81-99-275-6780 (T.T.)
}

Received: 25 August 2020; Accepted: 17 September 2020; Published: 18 September 2020

\begin{abstract}
It is important and useful to consider information provided by family members about individuals with memory complaints' instrumental activities of daily living (IADL). The purpose of this study was to clarify the characteristics and relevance of individuals with memory complaints' IADL and behavioral and psychological symptoms of dementia (BPSD) assessed from the perspective of the family members using the Process Analysis of Daily Activity for Dementia and short version Dementia Behavior Disturbance scale. A self-administered questionnaire was sent to 2000 randomly selected members of Consumer's Co-operative Kagoshima, and 621 responded. Of the returned responses, there were 159 participants who answered about individuals with memory complaints. The stepwise multiple regression analysis was used to examine the association between IADL and BPSD. The result showed that many IADL of the individuals with memory complaints were associated with BPSD of apathy, nocturnal wakefulness, and unwarranted accusations, adjusted for age, gender, and the observation list for early signs of dementia. In addition, each IADL was associated with BPSD of apathy, nocturnal wakefulness, and dresses inappropriately. Modifying lifestyle early on when families recognize these changes may help maintain and improve the long-term quality of life of the individuals with memory complaints and their family.
\end{abstract}

Keywords: activities of daily living; behavioral and psychological symptoms of dementia; community-dwelling older adults; caregiver; memory complaints

\section{Introduction}

Individuals suspected to have dementia may overestimate their functional abilities, and therefore it is important to consider the information provided by family members while diagnosing cases in the early stages of the disease [1]. There have been also reports that older adults with mild cognitive impairment (MCI) are less aware of changes in instrumental activities of daily living (IADL) due to 
reduced self-awareness [2,3]. Caregivers' and especially family members' reports on IADL have been found useful for the diagnosis of dementia [4].

Previous studies on family members of people with MCI and mild Alzheimer's disease (AD) have identified the caregiver burden and its associated factors [5-9], family members' perceptions of patients' behavioral and psychological symptoms of dementia (BPSD) [10,11], and the association between activities of daily living (ADL) and BPSD from the family members' perspective [12-14].

Studies show that complex IADL, such as management of money and medication, decline in the early stages of MCI and mild AD [15-17]. Additionally, our earlier survey revealed that functions related to the ability to use the telephone, shopping, cooking, housekeeping, managing finances, and managing medication decline after subjective memory complaints emerge [18]. Furthermore, several reports suggest that BPSD begin during the MCI stage, with the emergence of symptoms of depression, dysphoria, apathy, irritability, and sleep disturbances (in order of frequency) [19-22].

Previous studies have revealed that IADL independence declines and BPSD (apathy, depression) emerge from the MCI stage, and the association between the two has already been confirmed [23-25]. Additionally, studies have highlighted that MCI can lead to BPSD and a decline in IADL [14,25]. For example, it has also been shown that apathy is a predictor of complex ADL, especially in mild AD with a clinical dementia rating $=0.5$ [26]. Apathy may appear even at the stage of subjective memory complaints, and it may be related to IADL, but the current situation is that there is no knowledge.

On the other hand, family members who routinely support individuals with memory complaints are aware of the care recipient's problems; therefore, they seek appropriate support from the early stages of dementia. There were studies that examined the association between IADL and BPSD in $\mathrm{AD}$ patients from the information provided by the caregiver [13,27]. However, few studies use family members' reports of patients' IADL abilities to examine the association between IADL and BPSD before the onset. The Process Analysis of Daily Activity for Dementia (PADA-D) developed by our group is an ADL evaluation method that can be used to analyze the impairment in each daily activity associated with cognitive decline at the process level [23]. This method allows us to derive an in-depth understanding of the status of ADL performance of individuals with memory complaints by collecting data from caregivers and family members.

The present study aimed to clarify the characteristics and relevance of IADL and BPSD in individuals with memory complaints, assessed from the perspective of family members by using the PADA-D. This study provides an understanding of family members' perception of IADL and BPSD in community-dwelling older adults. Additionally, its findings may help provide support for affected individuals and their family members from the stage at which memory complaints and subsequent issues emerge.

\section{Materials and Method}

\subsection{Study Design}

This was a cross-sectional study using a self-administered questionnaire.

\subsection{Ethical Considerations}

This study was approved by the ethics board of Kagoshima University. The questionnaire explained to participants what the purpose of the research was and that the information collected would be kept confidential and used only for the purpose of this study. By answering the survey questions, the respondents indicated their agreement to participate. Our study protocol was approved by the Ethics Committee on Epidemiological Studies, Kagoshima University on 27 December 2018. Its identification code is 170377(370)-2. 


\subsection{Participant}

Consumer's Co-operative (CO-OP) is an autonomous association of consumers who volunteer to fulfill common needs and aspirations. CO-OP Kagoshima is a private enterprise with deep ties to the local community; it assists the residents with various activities, including conducting trips to stores, delivery, and other benefits that may support functioning. At CO-OP Kagoshima, many employees in stores and delivery businesses struggle to communicate with people with dementia or suspected dementia. In December 2018, a self-administered questionnaire was sent to 2000 randomly selected members of CO-OP Kagoshima who were 60 years old and over. We received 621 responses (recovery rate: $31 \%$ ). The questionnaire included an enclosed reply envelope; thus, the responses were collected via mail. The survey period was from December 2018 to January 2019. Of the returned responses, there were 159 participants (individuals with memory complaints' family) who answered about individuals with memory complaints. The individuals with memory complaints in this study were the participants' family, and who were worried about memory complaints. In addition, the participants answered yes to the question "Is there any family member who worried about memory complaints and feel inconveniences in life?".

\subsection{Method}

\subsubsection{Procedure}

The participants answered questions related to the following regarding the individuals with memory complaints: 1 . characteristics of individuals with memory complaints, 2 . IADL-8 performance of PADA-D (ability to use the telephone, shopping, cooking, housekeeping, use modes of transportation, laundry, managing finances, managing medication), 3. the short version of the 28-item Dementia Behavior Disturbance scale (DBD13) and 4. observation list for early signs of dementia (OLD).

\subsubsection{Measurements}

\section{Characteristics of Individuals with Memory Complaints}

Characteristics of individuals with memory complaints data were collected in the questionnaire. Items assessed for age, gender, residence, living situation (living alone or with family, number of cohabitants), level of care needed (the Japanese long-term care insurance: LTCI) [28,29], and work status (working or not working). Other items assessed feeling of health (very good, good, bad, or very bad) as seen by the participants (objective), degree of pain, and hobby involvement (or hobbies).

\section{PADA-D}

We used PADA-D to evaluate the IADL of the individuals with memory complaints. PADA-D can divide the performance of daily living activities by those with cognitive decline into processes and analyze ADL in detail. Five occupational therapists and two dementia specialists collaborated to determine the processes and actions that make up the process (actions) to be included from the Physical Self-Maintenance Scale and Lawton IADL scale. The PADA-D consists of a total of 14 activity performances (6 basic ADL performances and 8 IADL performances). Each activity performance is divided into five processes and three actions (Table 1). As an example, Table 2 demonstrates how "Ability to use the telephone" is divided into processes and actions. Tables S1-S7 show processes and actions of the other IADL performance. In PADA-D, activities' performances are arranged in a time series from the beginning to the end of an action, and it is possible to clearly indicate which process is impaired. The examiner judges the actions by "doing (YES)" and "not doing (NO)," granting points for "doing (YES)." Three points are available for 1 process, 15 points for 1 performance, and a total of 210 points for the 14 performances. The final scale with the items that were selected had high internal consistency and criterion validity (Cronbach's $\alpha=0.96$ ) [30] 
Table 1. List of processes of the PADA-D.

\begin{tabular}{|c|c|}
\hline \multicolumn{2}{|l|}{ IADL } \\
\hline Performance & Process \\
\hline Ability to use the telephone & $\begin{array}{l}\text { Call others } \\
\text { Talk on the phone } \\
\text { Hang up the phone } \\
\text { Notice the phone ring } \\
\text { Answer and talk on the phone }\end{array}$ \\
\hline Shopping & $\begin{array}{l}\text { Enter the store } \\
\text { Go to the section } \\
\text { Find a product } \\
\text { Pay for the product } \\
\text { Take home the product }\end{array}$ \\
\hline Cooking & $\begin{array}{l}\text { Plan a meal } \\
\text { Prepare the food (wash, cut, and heat the ingredients) } \\
\text { Season the ingredients (choose seasoning, etc.) } \\
\text { Plate the food } \\
\text { Set the table }\end{array}$ \\
\hline Housekeeping & $\begin{array}{l}\text { Clean up after a meal } \\
\text { Managing daily necessities } \\
\text { Management of bedding } \\
\text { Clean the house } \\
\text { Garbage dumping }\end{array}$ \\
\hline Use modes of transportation & $\begin{array}{c}\text { Take a taxi } \\
\text { Take a bus or train } \\
\text { Ride a bicycle } \\
\text { Drive a mobility scooter } \\
\text { Choose an appropriate mode of transportation }\end{array}$ \\
\hline Laundry & $\begin{array}{c}\text { Put the laundry in the washing machine } \\
\text { Start the washing machine } \\
\text { Operate the dryer or find another effective means to dry the laundry } \\
\text { Take in and fold the laundry } \\
\text { Put the clothes in the chest/closet }\end{array}$ \\
\hline Managing finances & $\begin{array}{c}\text { Handle cash } \\
\text { Use cash on a daily life } \\
\text { Understand household expenses } \\
\text { Use the bank and the post office } \\
\text { Use electronic money }\end{array}$ \\
\hline $\begin{array}{l}\text { Managing } \\
\text { medication }\end{array}$ & $\begin{array}{c}\text { Keep the regular time to take medication } \\
\text { Take out the prescribed medicine } \\
\text { Check the correct quantity of medicine } \\
\text { Take medicine correctly } \\
\text { Keep track of leftover medicine }\end{array}$ \\
\hline \multicolumn{2}{|l|}{ BADL } \\
\hline Performance & Process \\
\hline Toileting & $\begin{array}{l}\text { Get into the restroom } \\
\text { Sit on the toilet seat } \\
\text { Excreting } \\
\text { Do post-processing } \\
\text { Leave the restroom }\end{array}$ \\
\hline
\end{tabular}


Table 1. Cont.

\begin{tabular}{|c|c|}
\hline Feeding & $\begin{array}{l}\text { Choose a dish } \\
\text { Shape the food easy to eat } \\
\text { Bring food to the mouth } \\
\text { Eating } \\
\text { Finish the meal }\end{array}$ \\
\hline Dressing & $\begin{array}{l}\text { Choose clothes } \\
\text { Take off clothes } \\
\text { Put on clothes } \\
\text { Put on and take off socks } \\
\text { Wear and take off shoes }\end{array}$ \\
\hline Grooming & $\begin{array}{c}\text { Brush teeth } \\
\text { Wash the face } \\
\text { Shave/Put on makeup } \\
\text { Dress hair } \\
\text { Cut nails }\end{array}$ \\
\hline Mobility & $\begin{array}{c}\text { Get up } \\
\text { Move around in one room } \\
\text { Move between one room and others } \\
\text { Go out of the house } \\
\text { Go to neighborhood }\end{array}$ \\
\hline Bathing & $\begin{array}{l}\text { Take off clothes } \\
\text { Pouring hot water over your body } \\
\text { Soak in the bath } \\
\text { Wash body and hair } \\
\text { Dry off hair and body }\end{array}$ \\
\hline
\end{tabular}

PADA-D: Process Analysis of Daily Activity for Dementia. IADL: instrumental activities of daily living. BADL: basic activities of daily living.

Table 2. Example of the PADA-D (ability to use the telephone).

\begin{tabular}{|c|c|c|c|c|c|}
\hline \multirow[t]{4}{*}{ Score } & \multirow{4}{*}{$\begin{array}{c}\text { Process } \\
\text { 1. Call others }\end{array}$} & \multirow{4}{*}{$\begin{array}{l}\text { Actions That Make up the Process } \\
\text { (1) Pick up the phone } \\
\text { (2) Press or touch the call button } \\
\text { (3) Call the number (registered button, etc.) }\end{array}$} & \multicolumn{2}{|c|}{ Check } & \multirow[t]{4}{*}{ Remarks } \\
\hline & & & YES & $\mathrm{NO}$ & \\
\hline & & & YES & $\mathrm{NO}$ & \\
\hline & & & YES & NO & \\
\hline \multirow{3}{*}{\multicolumn{2}{|c|}{ 2. Talk on the phone }} & (1) Hold the phone on ear & YES & $\mathrm{NO}$ & \\
\hline & & (2) Confirm the conversation partner & YES & $\mathrm{NO}$ & \\
\hline & & (3) Tell the matter & YES & NO & \\
\hline \multirow{3}{*}{\multicolumn{2}{|c|}{ 3. Hang up the phone }} & (1) End the conversation & YES & $\mathrm{NO}$ & \\
\hline & & (2) Hold the phone away from the ear & YES & $\mathrm{NO}$ & \\
\hline & & (3) Press the call end button & YES & $\mathrm{NO}$ & \\
\hline \multirow{3}{*}{\multicolumn{2}{|c|}{ 4. Notice the phone ring }} & (1) Find the phone & YES & $\mathrm{NO}$ & \\
\hline & & (2) Confirm who is talking on the phone & YES & $\mathrm{NO}$ & \\
\hline & & (3) Press the call button & YES & $\mathrm{NO}$ & \\
\hline \multirow{3}{*}{\multicolumn{2}{|c|}{$\begin{array}{l}\text { 5. Answer and talk on } \\
\text { the phone }\end{array}$}} & (1) Hold the phone on ear & YES & NO & \\
\hline & & (2) Ask the purpose on the phone & YES & $\mathrm{NO}$ & \\
\hline & & (3) Have a conversation with each other & YES & $\mathrm{NO}$ & \\
\hline
\end{tabular}

Enter the score for each process in the score column after checking "YES" or "NO" for the three actions. We changed some words in the PADA-D we developed. 
We used the DBD13 to evaluate BPSD of the individuals with memory complaints. The DBD13 was created in Japan as a short version of the DBD [31] for easy evaluation of BPSD in the clinical scene. Thirteen items with a high frequency of appearance and large change due to intervention were extracted, and these have an extremely significant correlation $(r=0.96, p<0.0001)$ with the DBD. In addition, the DBD13 was shown to be reliable and valid [32]. We rated them on a five-point scale, from 0 (not at all) to 4 (always). The higher the total score of the DBD 13, the more severe the obstacle, and the total score is 52 points.

\section{OLD}

We used the OLD to understand the initial symptoms of dementia, such as memory complaints. The OLD is an evaluation of an observation formula consisting of 12 items that are likely to appear early in $\mathrm{AD}$. We evaluated them on a two-point scale, 1 (yes) or 2 (no). If more than four items are "yes", dementia is suspected. The OLD was shown to be reliable and valid [33].

\subsubsection{Statistical Analysis}

Once data were gathered, totaled, and averaged, characteristics of individuals with memory complaints were considered. We calculated the appearance rate of items in the DBD13 (the percentage of respondents who answered "sometimes", "frequently", or "always"). Next, the multiple regression analysis was performed after checking data with a normal distribution using the Shapiro-Wilk test. If a normal distribution was not confirmed, the Durbin-Watson test was performed to confirm the normality of the residuals. The stepwise multiple regression analysis was used to examine the association between living activities and BPSD. The dependent variable was PADA-D total score, the independent variables were item scores of the DBD13, and the covariates were age, gender, and OLD total score. Finally, the stepwise multiple regression analysis was used to examine in detail which items of BPSD were related to daily activities. The dependent variables were each total score of PADA-D 8 IADL performance, the independent variables were item scores of the DBD13, and the covariates were age, gender, and OLD total score. If answers were missing, they were treated as missing values. All statistical analyses were performed using IBM SPSS Statistics ver25.0, and the significance level was set at $5 \%$ or $1 \%$.

\section{Results}

\subsection{Characteristics of Individuals with Memory Complaints}

Table 3 shows the characteristics of persons concerned. The average age was $84.4 \pm 8.8$ years old. They were mostly women $(62.3 \%), 66 \%$ of whom lived with family. The average PADA-D total score was $55.8 \pm 40.9$ points, the average OLD total score was $6.4 \pm 4.1$ points, and the median DBD 13 total score was 14.0 points. The appearance rates of sub-items in the DBD13 were No1. "Ask the same question repeatedly" (79.7\%), No2. "Loses, misplaces, or hides things" (65.1\%), No6. "Sleeps excessively during the day" (60.3\%), and No3. "Lack of interest in daily activities" (58.3\%) in descending order. Other features were as follows: 55\% looked healthy. The median level of care needed (LTCI) was Requiring Support 2 (a condition in which the ability to perform IADL was slightly reduced and some support was needed to maintain and improve functions). A total of $88 \%$ had no work, $66 \%$ had objective pain, and $31 \%$ had hobbies. 
Table 3. Characteristics of individuals with memory complaints.

\begin{tabular}{cc} 
Parameter & $\begin{array}{c}\text { Individuals with Memory Complaints } \\
(\boldsymbol{n}=\mathbf{1 5 9 )}\end{array}$ \\
age, mean (SD), year & $84.4(8.8)$ \\
female & $99(62.3)$ \\
living with family & $107(66.0)$ \\
OLD total score (SD) & $55.8(40.9)$ \\
PADA-D IADL total score (SD), max 120 & $6.5(4.1)$ \\
DBD13 total score median (25th-75th percentiles) & $14.0(7.0-21.5)$ \\
DBD13 items appearance rate (sometimes-always) & \\
No1. Ask the same question repeatedly & 79.7 \\
No2. Loses, misplaces, or hides things & 65.1 \\
No3. Lack of interest in daily activities & 58.3 \\
No4. Wake up at night for no obvious reason & 27.3 \\
No5. Makes unwarranted accusations & 24.5 \\
No6. Sleeps excessively during the day & 60.3 \\
No7. Paces up and down & 13.1 \\
No8. Repeats the same action over and over & 18.4 \\
No9. Is verbally abusive, curse & 19.6 \\
No10. Dresses inappropriately & 25.9 \\
No11. Refuses to be helped with personal care & 24.0 \\
No12. Hoards things for no obvious reason & 23.2 \\
No13. Empties drawers or closets & 11.6 \\
\hline
\end{tabular}

Data are presented as $n$ (\%). PADA-D: Process Analysis of Daily Activity for Dementia. OLD: observation list for early signs of dementia. DBD: Dementia Behavior Disturbance scale.

\subsection{PADA-D Total Score and DBD13 Sub-Item Score}

Table 4 shows the results of the stepwise multiple regression analysis of PADA-D total score and DBD13 sub-item score. PADA-D total score was associated with No3. "Lack of interest in daily activities" ( $\beta=-0.262, p=0.007)$, No4. "Wake up at night for no obvious reason" $(\beta=-0.277$, $p=0.003)$, and No5. "Makes unwarranted accusations" $(\beta=0.193, p=0.017)$ in the DBD13.

Table 4. The stepwise multiple regression analysis between PADA-D total score and DBD13 items.

\begin{tabular}{cccccc}
\hline Parameter & B & $\beta$ & $p$-Value & 95\% CI, Lower & 95\% CI, Upper \\
\hline No.3 Lack of interest in daily activities & -7.675 & -0.262 & 0.007 & -13.247 & -2.108 \\
No.4 Wake up at night for no obvious reason & -8.763 & -0.277 & 0.003 & -14.562 & -2.964 \\
No.5 Makes unwarranted accusations & 7.149 & 0.193 & 0.017 & 1.283 & 13.016 \\
\hline$\beta:$ regression coefficients. CI: confidence intervals. PADA-D: Process Analysis of Daily Activity for Dementia. DBD: \\
$\quad$ Dementia Behavior Disturbance scale. Adjusted R ${ }^{2}$ : 0.49. Covariate: age ( $\left.\beta=-0.24, p=0.002\right)$, OLD total score \\
$\quad(\beta=-0.26, p=0.002)$.
\end{tabular}

\subsection{PADA-D 8 IADL Performance and DBD13 Sub-Item Score}

Table 5 shows the results of the stepwise multiple regression analysis of each total score of PADA-D 8 IADL performance and DBD13 sub-item score. Many of the IADL were associated with multiple BPSD such as apathy, nocturnal wakefulness, and dresses inappropriately. 
Table 5. Multiple regression analysis between PADA-D IADL performance and DBD13 items.

\begin{tabular}{|c|c|c|c|c|c|c|c|c|c|}
\hline & \multirow[b]{2}{*}{ Parameter } & \multicolumn{8}{|c|}{ PADA-D IADL Performance } \\
\hline & & $\begin{array}{l}\text { Ability to use } \\
\text { the Telephone }\end{array}$ & Shopping & Cooking & Housekeeping & $\begin{array}{c}\text { Use Modes of } \\
\text { Transportation }\end{array}$ & Laundry & $\begin{array}{c}\text { Managing } \\
\text { Finances }\end{array}$ & $\begin{array}{c}\text { Managing } \\
\text { Medication }\end{array}$ \\
\hline \multirow{13}{*}{$\begin{array}{c}\text { DBD13 } \\
\text { item }\end{array}$} & No1. Ask the same question repeatedly & & & & & $\begin{array}{c}-0.19 \\
(-1.46,-0.17) *\end{array}$ & & & $\begin{array}{c}-0.17 \\
(-1.44,-0.05) \text { * }\end{array}$ \\
\hline & No2. Loses, misplaces, or hides things & & & & & & & & \\
\hline & No3. Lack of interest in daily activities & $\begin{array}{c}-0.36 \\
(-1.95,-0.76) * *\end{array}$ & $\begin{array}{c}-0.25 \\
(-2.13,-0.36)\end{array}$ & & & $\begin{array}{c}-0.31 \\
(-1.86,-0.68) * *\end{array}$ & & & $\begin{array}{c}-0.32 \\
(-1.98,-0.66)\end{array}$ \\
\hline & No4. Wake up at night for no obvious reason & $\begin{array}{c}-0.32 \\
(-1.91,-0.67) \text { ** }\end{array}$ & $\begin{array}{c}-0.19 \\
(-1.99,-0.08) *\end{array}$ & $\begin{array}{c}-0.29 \\
(-2.39,-0.58) \text { * }\end{array}$ & $\begin{array}{c}-0.29 \\
(-2.01,-0.52)\end{array}$ & & $\begin{array}{c}-0.38 \\
(-2.84,-1.01)^{* *}\end{array}$ & $\begin{array}{c}-0.34 \\
(-2.01,-0.78)^{* *}\end{array}$ & \\
\hline & No5. Makes unwarranted accusations & & & & & & $\begin{array}{c}0.24 \\
(0.39,2.47) *\end{array}$ & $\begin{array}{c}0.16 \\
(0.07,1.51)^{*}\end{array}$ & \\
\hline & No6. Sleeps excessively during the day & & & & & & & & \\
\hline & No7. Paces up and down & & & & & & & & \\
\hline & No8. Repeats the same action over and over & & & & & & & & \\
\hline & No9. Is verbally abusive, curse & & & & & & & & \\
\hline & No10. Dresses inappropriately & $\begin{array}{c}-0.20 \\
(-1.76,-0.29)\end{array}$ & & & & & & $\begin{array}{c}-0.20 \\
(-1.83,-0.32) \text { * }\end{array}$ & $\begin{array}{c}-0.28 \\
(-2.49,-0.66)\end{array}$ \\
\hline & No11. Refuses to be helped with personal care & & & & & & & & $\begin{array}{c}0.20 \\
(0.28,2.05) \text { * }\end{array}$ \\
\hline & No12. Hoards things for no obvious reason & $\begin{array}{c}0.19 \\
(0.28,1.55) *\end{array}$ & & & & & & & \\
\hline & No13. Empties drawers or closets & & & & & & & & \\
\hline age & & & $\begin{array}{c}-0.38 \\
(-0.37,-0.16)^{* *}\end{array}$ & $\begin{array}{c}-0.21 \\
(-0.27,-0.04)\end{array}$ & $\begin{array}{c}-0.17 \\
(-0.20,-0.01)\end{array}$ & & $\begin{array}{c}-0.17 \\
(-022,-0.01)\end{array}$ & $\begin{array}{c}-0.22 \\
(-0.19,-0.05)\end{array}$ & $\begin{array}{c}-0.22 \\
(-0.22,-0.04)\end{array}$ \\
\hline gender & & $\begin{array}{c}-0.14 \\
(-2.67,-0.17)\end{array}$ & & $\begin{array}{c}-0.19 \\
(-0.55,-0.03) \text { * }\end{array}$ & & $\begin{array}{c}-0.30 \\
(-5.01,-1.58) * *\end{array}$ & & & \\
\hline OLD & & & & & $\begin{array}{c}-0.24 \\
(-0.56,-0.09) *\end{array}$ & & $\begin{array}{c}-0.23 \\
(-0.59,-0.08)\end{array}$ & $\begin{array}{c}-0.31 \\
(-0.57,-0.21)^{* *}\end{array}$ & \\
\hline & Adjusted $\mathrm{R}^{2}$ & 0.51 & 0.40 & 0.25 & 0.27 & 0.44 & 0.26 & 0.51 & 0.41 \\
\hline
\end{tabular}

Data were presented as regression coefficients $\beta$ ( $95 \%$ confidence intervals. CI lower, upper). * $p<0.05 .{ }^{* *}: p<0.001$. PADA-D: Process Analysis of Daily Activity for Dementia. DBD:

Dementia Behavior Disturbance scale, OLD: observation list for early signs of dementia. 


\subsubsection{Ability to Use the Telephone}

This was associated with No3. "Lack of interest in daily activities" ( $\beta=-0.36, p<0.001)$, No4. "Wake up at night for no obvious reason" ( $\beta=-0.32, p<0.001)$, No10. "Dresses inappropriately" $(\beta=-0.02, p=0.007)$, and No12. "Hoard things for no obvious reason" ( $\beta=0.19, p=0.005)$ in the DBD13.

\subsubsection{Shopping}

This was associated with No3. "Lack of interest in daily activities" $(\beta=-0.25, p=0.006)$ and No4. "Wake up at night for no obvious reason" $(\beta=-0.19, p=0.035)$ in the DBD13.

\subsubsection{Cooking}

This was associated with No4. "Wake up at night for no obvious reason" $(\beta=-0.29, p=0.001)$ in the DBD13.

\subsubsection{Housekeeping}

This was associated with No4. "Wake up at night for no obvious reason" ( $\beta=-0.29, p=0.001)$ in the DBD13.

\subsubsection{Use modes of Transportation}

This was associated with No1. "Ask the same question repeatedly" $(\beta=-0.19, p=0.014)$ and No3. "Lack of interest in daily activities" $(\beta=-0.31, p<0.001)$ in the DBD13.

\subsubsection{Laundry}

This was associated with No4. "Wake up at night for no obvious reason" $(\beta=-0.38, p<0.001)$ and No5. "Makes unwarranted accusations" $(\beta=-0.24, p=0.008)$ in the DBD13.

\subsubsection{Managing Finances}

This was associated with No4. "Wake up at night for no obvious reason" $(\beta=-0.34, p<0.001)$, No5. "Makes unwarranted accusations" ( $\beta=0.16, p=0.032)$, and No10. "Dresses inappropriately" $(\beta=-0.20, p=0.006)$ in the DBD13.

\subsubsection{Managing Medication}

This was associated with No1. "Ask the same question repeatedly" $(\beta=-0.17, p=0.037)$, No3. "Lack of interest in daily activities" $(\beta=-0.32, p<0.001)$, No10. "Dresses inappropriately" $(\beta=-0.28, p=0.001)$, and No11. "Refuses to be helped with personal care" $(\beta=020, p=0.010)$ in the DBD13.

\section{Discussions}

In this study, we investigated the association between IADL ability and BPSD in individuals experiencing memory complaints, from their family members' perspective, by collecting detailed information about the daily activities of community-dwelling older adults belonging to CO-OP Kagoshima. We found that the daily activities of the individuals with memory complaints were associated with BPSD such as apathy, nocturnal wakefulness, and unwarranted accusations. Additionally, each IADL was associated with age and BPSD such as apathy, nocturnal wakefulness, and dresses inappropriately.

The individuals with memory complaints included in this study were aged over 80 years, the majority of them were female, and about half of them lived with someone else. Additionally, their ability to perform IADL was slightly low according to their level of care needed (Requiring 
Support 2), indicating that they needed some kind of support. Further, several of them experienced objective pain, muscle weakness, and hearing loss. The average total OLD scores suggested that some of them may have had early dementia. Further, their median DBD13 total score indicated that some of them may have experienced BPSD symptoms such as memory loss, losing items, sleeps excessively during the day, and apathy. We found that family members noticed memory changes and the emergence of BPSD.

According to previous studies on IADL and BPSD reported by family members of AD patients, the Functional Activities Questionnaire (FAQ) positively correlated with all items, expect for one (depression), in the Neuropsychiatric Inventory (NPI) [13]. Additionally, sleep disorders (nocturnal wakefulness) in AD patients were highly associated with anxiety levels (OR2.1) and ADL disorder (OR1.6) [12]. Apathy for normal and MCI participants was moderately associated with IADL [25]. Vascular dementia (VaD) patients' level of apathy has also been reported as a predictor of BADL/IADL performance [34]. BPSD, such as depression, apathy, agitation, irritability, disinhibition, and anxiety, are also seen in older adults with cognitive impairment and no dementia (CIND), and these symptoms are reported to be associated with functional limitations in basic ADL and IADL [23]. In individuals with MCI, this suggests that changes in cognitive function may affect daily activity, and that depression and apathy may have a strong effect on everyday function [14]. As different scales are used to assess daily activities and BPSD, it is difficult to compare the present results with those of previous studies. However, the present finding of an association of IADL with apathy, nocturnal wakefulness, and unwarranted accusations is in line with the findings of previous studies mentioned above. For example, apathy disrupts lifestyle habits and affects overall life, including health and hygiene, and sleep disorders can hinder the execution of daily activities at appropriate times. Additionally, unwarranted accusations could make interpersonal relationships difficult and could lead to caregivers' burden. These findings suggest a bidirectional association between IADL and BPSD before the onset.

Next, we examined the association between eight IADL and BPSD individually. Each ADL was associated with multiple BPSD, and most were associated with apathy, nocturnal wakefulness, and dresses inappropriately. This finding confirmed that BPSD may be linked to impaired IADL ability. Additionally, we clarified that shopping, cooking, housekeeping, laundry, managing finances, and managing medication were related to aging. We confirmed that these factors cause a decline in IADL ability.

For instance, "Laundry" in the PADA-D comprises the following five processes: "Put the laundry in the washing machine," "Start the washing machine," "Operate the dryer or find another effective means to dry the laundry," "Take in and fold the laundry," and "Put the clothes in the chest/closet." The present findings revealed that "Laundry" was significantly associated with nocturnal wakefulness and unwarranted accusations. Nocturnal wakefulness may lead to reduced physical activity during the day [35] and circadian rhythm disorders [36], which may delay and impair the ability to dry and retrieve laundry. Additionally, unwarranted accusations could be thought of as a manifestation of stress in not being able to do what was previously easy [5]. It is possible that the motivation to carry out a daily activity such as laundry may decrease.

Similarly, "Ability to use the telephone" comprises the following five processes: "Call others," "Talk on the phone," "Hang up the phone," "Notice the phone ring," and" Answer and talk on the phone." The present findings revealed that "Ability to use the telephone" was significantly associated with apathy, nocturnal wakefulness, dresses inappropriately, and hoarding things. Apathy was strongly associated with IADL in MCI patients [37], and it may interfere with the act of answering or getting the phone. Additionally, a previous study reported that hoarding things implied the presence of memory complaints [5]. This suggests that memory decline may lead to difficulties with memorizing a message or responding to conversations with callers.

The present study has several limitations. First, we did not collect information on individuals with memory complaints' medical history of MCI or dementia. Based on the OLD results and background information, several of them could be inferred to be at the SMC or MCI stage. However, we cannot 
be sure. Second, we did not collect the caregivers' background information. There may have been biases regarding their care recipients, but this was unclear because we did not collect information on the association between the caregivers and care recipients. Third, it may be difficult to generalize the findings given that the participants were members of CO-OP Kagoshima, who are more aware of health issues as compared to the general population. Forth, the recovery rate in this study was $31 \%$. Some studies were investigating with a recovery rate of $30-40 \%$ for community-dwelling older adults $[38,39]$. The recovery rate of this study is considered to be rather low, so we will consider a methodology to increase the recovery rate in future studies. Finally, the fact that the participants' educational background was not investigated is one of the defects of this study. This is significant as a low level of education has been reported to be a risk factor for MCI and AD [40].

Despite these limitations, the results of this study indicate that family members are aware of individuals with memory complaints' decline in IADL abilities and BPSD, which are likely to appear in MCI and the early stages of dementia. Accordingly, the implementation of interventions to modify the lifestyle of such individuals early, specifically when families recognize these changes, may help maintain and improve the long-term quality of life of care recipients and their family. Furthermore, this awareness needs to be taken into consideration during early medical consultations and appropriate support should be provided.

\section{Conclusions}

This study showed that the family members were well aware of individuals with memory complaints' IADL and BPSD. Further, the results revealed that many of IADL were associated with multiple BPSD, particularly apathy and nocturnal wakefulness. We consider that investigating IADL and BPAD from a family who can observe the individuals with memory complaints in detail by a specific evaluation (like PADA-D) could help in accurately understanding the behavioral changes of them. In addition, bidirectional intervention of IADL and BPSD such as apathy and nocturnal wakefulness from the time the family notices behavioral changes may prevent progression to $\mathrm{MCI}$ and dementia and reduce the caregivers' burden.

Supplementary Materials: The following are available online at http://www.mdpi.com/1660-4601/17/18/6831/s1, Table S1: Shopping in PADA-D, Table S2: Cooking in PADA-D, Table S3: Housekeeping in PADA-D, Table S4: Use modes of transportation in PADA-D, Table S5: Laundry in PADA-D, Table S6: Managing finances in PADA-D, Table S7: Managing medication in PADA-D.

Author Contributions: Conceptualization, Y.I.; methodology, Y.I. and T.T.; formal analysis, Y.I., M.H. and G.H.; investigation, G.H., M.M. and E.U.; writing-Original draft preparation, Y.I. and T.T.; supervision, T.T. All authors have read and agreed to the published version of the manuscript.

Funding: This research was funded by CO-OP Insurance Support Project for Health Promotion 2018.

Acknowledgments: This work got the cooperation of CO-OP Kagoshima.

Conflicts of Interest: The authors declare no conflict of interest.

\section{References}

1. Steven, A.M.; Michaels, K.; Padilla, M.; Pelton, G.; Bell, K.; Marder, K.; Stern, Y.; Devanand, D.P. Functional significance of mild cognitive impairment in elderly patients without a dementia diagnosis. Am. J. Geriatr. Psychiatry 1999, 7, 213-220.

2. Maria, S.; Raquel, S.; Marcela, N.; Tatiana, B.; Rachel, R.; Bianca, T.; Pedro, S.; Daniel, M.; Jerson, L.; Marcia, D. Awareness of disease is different for cognitive and functional aspects in mild Alzheimer's disease: A one-year observation study. J. Alzheimers Dis. 2015, 43, 905-913.

3. Kayla, S.; Tyler, B.; Virginia, W. Differences in self-awareness of functional deficits between amnestic single-and multidomain mild cognitive impairment. J. Clin. Exp. Neuropsychol. 2019, 41, 544-553.

4. Tabert, M.H.; Albert, S.M.; Borulhova-Milov, L.; Camacho, Y.; Pelton, G.; Liu, X.; Stern, Y.; Devanand, D.P. Functional deficits in patients with mild cognitive impairment. Neurology 2002, 58, 758-764. [CrossRef] 
5. Kamiya, M.; Sakurai, T.; Ogama, N.; Maki, Y.; Toba, K. Factors associated with increased caregiver's burden in several cognitive stage of Alzheimer's disease. Geriatr. Gerontol. Int. 2014, 14, 45-55. [CrossRef]

6. Kang, H.S.; Myung, W.; Na, D.L.; Kim, S.Y.; Lee, J.-H.; Han, S.-H.; Choi, S.H.; Kim, S.Y.; Kim, S.; Kim, D.K. Factors associated with caregiver burden in patients with Alzheimer's disease. Psychiatry Investig. 2014, 11, 152-159. [CrossRef]

7. Richardson, T.J.; Lee, S.J.; Berg-Weger, M.; Grossberg, G.T. Caregiver health: Health of caregivers of Alzheimer's and other dementia patients. Curr. Psychiatry Rep. 2013, 15, 367. [CrossRef]

8. Akiyoshi, T.; Nakashima, Y.; Kusaba, T. Psychological processes undergone by caregivers for elderly family members with dementia during the early period following diagnosis of the disease. J. Jpn. Soc. Dement. Care 2019, 15, 470-479.

9. Seike, A.; Sakurai, T.; Sumigaki, C.; Tekeda, A.; Endo, H.; Toba, K. Verification of educational support intervention for Family caregivers of persons with dementia. J. Am. Geriatr. Soc. 2016, 64, 661-662. [CrossRef]

10. Gallo, J.L.; Schmidt, K.S.; Libon, D.J. Behavioral and psychological symptoms, neurocognitive performance, and functional independence in mild dementia. Dementia 2008, 7, 397-413. [CrossRef]

11. Lee, D.; Heo, S.; Yoon, S.-S.; Chang, D.; Lee, S.; Rhee, H.-Y.; Ku, B.; Park, K.-C. Sleep disturbance and predictive factors in caregivers of patients with mild cognitive impairment and dementia. J. Clin. Neurol. 2014, 10, 303-331. [CrossRef]

12. Mccurry, S.; Gibbons, L.; Logsdon, R.; Teri, L. Anxiety and nighttime behavioral disturbances: Awakenings in patients with Alzheimer's disease. J. Gerontol. Nurs. 2004, 30, 12-20. [CrossRef]

13. Tekin, S.; Fairbanks, L.; O'Connor, S.; Rosenberg, S.; Cummings, J. Activities of daily livings in Alzheimer's disease. Am. J. Geriatr. Psychiatry 2011, 9, 1.

14. Rog, L.; Park, L.; Harvey, D.; Huang, C.-H.; Mackin, S.; Farias, S. The independent contributions of cognitive impairment and neuropsychiatric symptoms to everyday function in older adults. Clin. Neuropsychol. 2014, 28, 215-236. [CrossRef]

15. Peres, K.; Chrysostome, V.; Fabrigoule, C.; Orgogozo, J.M.; Dartigues, J.F.; Barberger-Gateau, P. Restriction in complex activities of daily living in MCI. Neurology 2006, 67, 461-466. [CrossRef]

16. Mariani, E.; Monastero, R.; Ercolani, S.; Rinldi, P.; Mangialasche, F.; Costanzi, E.; Vitale, D.F.; Senin, U.; Mecocci, M. Influence of comorbidity and cognitive status on instrumental activities of daily living in amnestic mild cognitive impairment: Results from the ReGAI project. Int. J. Geriatr. Psychiatry 2008, 23, 523-530. [CrossRef]

17. Jekel, K.; Damian, M.; Wattmo, C.; Hausner, L.; Bullock, R.; Connelly, J.P.; Dubois, B.; Eriksdotter, M.; Ewers, M.; Graessel, E.; et al. Mild cognitive impairment and deficits in instrumental activities of daily living: A systematic review. Alzheimer's Res. Ther. 2015, 7, 17. [CrossRef]

18. Ikeda, Y.; Ogawa, N.; Yoshiura, K.; Han, G.; Maruta, M.; Hotta, M.; Tabira, T. Instrumental activities of daily living: The processes of involved in and performance of these activities by Japanese community-dwelling older adults with subjective memory complaints. Int. J. Environ. Res. Public Health 2019, 16, 2617. [CrossRef]

19. Hwang, T.; Masterman, D.; Ortiz, F.; Fairbanks, L.; Cummings, J. Mild cognitive impairment is associated with characteristics neuropsychiatric symptoms. Alzheimer Dis. Assoc. Disord. 2004, 18, 17-21. [CrossRef]

20. Beaulieu-Bonneau, S.; Hudon, C. Sleep disturbances in older adults with mild cognitive impairment. Int. Psychogeriatr. 2009, 21, 654-666. [CrossRef]

21. Palmer, K.; Berger, A.K.; Monastero, R.; Winblad, B.; Bäckman, L.; Fratiglioni, L. Predictors of progression from mild cognitive impairment to Alzheimer disease. Neurology 2007, 68, 1596-1602. [CrossRef]

22. Gallagher, D.; Fischer, C.; Iaboni, A. Neuropsychiatric symptoms in mild cognitive impairment: An update on prevalance, mechanisms, and clinical significance. Can. J. Psychiatry 2017, 62, 161-169. [CrossRef] [PubMed]

23. Okura, T.; Plassman, B.; Steffens, D.; Llewellyn, D.; Potter, G.; Langa, K. Prevalence of neuropsychiatric symptoms and their association with functional limitations in older adults in the United States: The aging, demographics, and memory study. J. Am. Geriatr. Soc. 2010, 58, 330-337. [CrossRef] [PubMed]

24. Lind, C.; Cindy, C.; Tam, C.; Victor, L. Depression and apathy affect functioning in community active subjects with questionable dementia and mild Alzheimer's disease. Int. J. Geriatr. Psychiatry 2007, 22, 431-437.

25. Rachel, B.; Megan, C.; Debra, M. Cognitive and neuropsychiatric correlates of functional impairment across the continuum of no cognitive impairment to dementia. Arch. Clin. Neuropsychol. 2018, 33, 795-807. 
26. Carolina, D.; Rodrigo, C.V.; Melissa, M.; Gada, M.; Fernando, H.; Andrea, S. Neuropsychiatric symptoms in Alzheimer's disease are the main determinants of functional impairment in advanced everyday activities. J. Alzheimers Dis. 2019, 67, 381-392.

27. Christine, Y.; Christine, M.; Louis, C.; Robin, K.; Bruce, M.; Joel, K. Neuropsychiatric symptoms predict functional status in Alzheimer's disease. J. Alzheimers Dis. 2015, 48, 863-869.

28. Tamiya, N.; Noguchi, H.; Nishi, A.; Reich, M.; Ikegami, N.; Hashimoto, H.; Shibuya, K.; Kawachi, I.; Campbell, J. Population ageing and wellbeing: Lessons from Japan's long-term care insurance policy. Lancet 2011, 378, 1183-1192. [CrossRef]

29. Tsutsui, T.; Muramatsu, N. Care-needs certification in the long-term care insurance system of Japan. J. Am. Geriatr. Soc. 2005, 53, 522-527. [CrossRef]

30. Tbira, T.; Hotta, M.; Ogawa, N.; Murata, M.; Yoshiura, K.; Maruta, M.; Ikeda, Y.; Ishikawa, T.; Ikeda, M. Development of Process Analysis of Daily Activitiy for Dementia (PADA-D) in community-dwelling patients with dementia. Jpn. J. Geriatr. Psychiatry 2019, 30, 923-931.

31. Baumgarten, M.; Becker, R.; Gauthier, S. Validity and reliability of the Dementia Behavior Disturbance Scale. J. Am. Geriatr. Soc. 1990, 38, 221-226. [CrossRef] [PubMed]

32. Machida, A. Estimation of the reliability and validity of the short version of the 28-item Dementia Behavior Disturbance scale. Nippon Ronen Igakkai Zasshi 2012, 49, 463-467. [CrossRef]

33. Hopman-Rock, M.; Tak, E.; Staats, P. Development and validation of the Observation List for early sings of Dementia (OLD). Int. J. Geriatr. Psychiatry 2001, 16, 401-414. [CrossRef]

34. Zawacki, T.; Gracce, J.; Paul, R.; Moster, D.; Ott, B.; Gordon, N.; Cohen, R. Behavioral problems predictors of functional abilities of vascular dementia patients. J. Neuropsychiatry Clin. Neurosci. 2002, 14, 3. [CrossRef] [PubMed]

35. Ishimaru, D.; Tanaka, H.; Nagata, Y.; Takabatake, S.; Nishikawa, T. Physical activity in severe dementia is associated with agitation rather than cognitive function. Am. J. Alzheimers Dis. Other Dement. 2019, 35, 1-7. [CrossRef] [PubMed]

36. Zhou, Q.; Jung, L.; Richards, K. The management of sleep and circadian disturbance in patients with dementia. Curr. Neurol. Neurosci. Rep. 2012, 12, 193-204. [CrossRef]

37. Ginsberg, T.; Powell, L.; Emrani, S.; Wasserman, V.; Higgins, S.; Chopra, A.; Cavalieri, T.; Libon, D. Instrumental activities of daily living, neuropsychiatric symptoms, and neuropsychological impairment in mild cognitive impairment. J. Am. Osteopath Assoc. 2019, 119, 96-101. [CrossRef]

38. Reinie, C.; Yu-Wei, C.; Lindy, C.; Julie, B.; Natasha, M. Subjective memory complaints and difficulty performing activities of daily living among older women in Australia. Aust. Occup. Ther. J. 2019, 66, $227-238$.

39. Shikimoto, R.; Sada, M.; Ninomiya, A.; Yoshida, K.; Ikeda, B.; Baba, T.; Mimura, M. Predictive factors associated with psychological distress of caregivers of people with dementia in Japan: A cross-sectional study. Int. Psychogeriatr. 2018, 30, 1089-1098. [CrossRef]

40. Mehlika, A.; Fatma, C. Which factors can we control the transition from mild cognitive impairment to dementia? J. Clin. Neurosci. 2020, 73, 108-110.

(C) 2020 by the authors. Licensee MDPI, Basel, Switzerland. This article is an open access article distributed under the terms and conditions of the Creative Commons Attribution (CC BY) license (http://creativecommons.org/licenses/by/4.0/). 